\title{
Varicella transmission in two samples of children with different social behaviour in the State of São Paulo, Brazil
}

\author{
A. L. F. YU ${ }^{1 *}$, M. AMAKU ${ }^{2}$, M. N. BURATTINI ${ }^{1}$, E. MASSAD ${ }^{1}$ \\ AND R.S. AZEVEDO ${ }^{1}$ \\ ${ }^{1}$ LIM 01/HCFMUSP, School of Medicine, University of São Paulo, São Paulo, Brazil \\ ${ }^{2}$ Physics Institute, University of São Paulo, São Paulo, Brazil
}

(Accepted 2 August 2001)

\section{SUMMARY}

In order to establish the differences in transmission pattern of varicella-zoster virus (VZV), a comparative seroepidemiological study was carried out in two different children samples.

Children aged 1-11 years, were randomly selected from state schools of São Paulo city, Brazil. Individuals aged 1-15 years were sampled by cluster from Caieiras city. Children aged 3 years or under from Caieiras were not attending school, while those from São Paulo were attending all-day nurseries or kindergarten. The presence of antibodies to VZV was analysed by ELISA technique. The force of infection and contact rate were determined by mathematical techniques. The average age of first infection was $2 \cdot 87 \pm 0.14$ years and $4.07 \pm 0.47$ years for São Paulo and Caieiras, respectively. The average force of infection estimated was 0.29 year $^{-1}$ for São Paulo and was $0 \cdot 26$ year $^{-1}$ for Caieiras. The proportion of seropositivity and the force of infection were higher in São Paulo school children up to 3 years of age compared with Caieiras children, where the social contact starts later. In conclusion, social changes affecting contact among children may influence varicella epidemiology.

\section{INTRODUCTION}

Varicella is generally mild and self-limited disease in otherwise healthy children. Varicella-zoster virus $(\mathrm{VZV})$ is transmitted person-to-person through direct contact with skin lesions and by airborne respiratory droplet infection. Patients with zoster can transmit varicella to susceptibles contacts [1-3]. The risk of complications appears to be higher in children under 1 year of age, in adults and immunocompromised persons [4]. Although less infectious than other diseases, varicella is a very contagious disease in closed populations and $80-90 \%$ of exposed susceptibles contacts will develop disease within households $[3,5,6]$.

The incubation period of varicella is $14-16$ days and

* Author for correspondence: Disciplina de Informática Médica, School of Medicine, University of São Paulo, Av. Dr. Arnaldo 455, CEP 01246-903, São Paulo, Brazil. cases are infectious several days before the onset of symptoms. In the absence of vaccination, almost all persons will acquire varicella over the course of lifetime [1, 3]. An apparent seasonality in reported cases is noted in temperate climates, with most cases reported during winter and spring. The seasonality is thought to be due primarily to high contact rates among children who attend school, where they have close contact during the coldest months [3, 7]. This seasonality is not seen in the tropics, which can be explained by heat, humidity and lack of exposure to the agent in confined spaces during the winter months. Varicella in the tropics mainly affects young adults, which could be attributable to agent-specific factors [8]. Varicella in temperate climates is a disease affecting predominantly pre-school and school-aged children. Varicella depends on closer contact to be transmitted compared to other infectious diseases, such as measles $[3,5,9]$. Accordingly, social changes 
that affect the pattern of contact among children may influence its epidemiology. There has been an increased incidence among children under 5 years old in the 1990s. Because of the increasing number of preschool-aged children now participating in organized group child care, many children 1-4 years of age now acquire varicella in day-care setting [3].

Serological data from a population can provide the profile of disease prevalence by age, allowing the estimation of the age-related force of infection. Mathematical models have been developed to determine whether changes in contact rates between and within different age groups could be described and understood regarding transmission dynamics of viral infection among different groups of children. The force of infection in viral diseases shows a pronounced age dependence, which is probably related to the increased transmission among school children [10].

This study aimed to quantify the differences in varicella transmission in two samples of children with different social behaviour in the State of São Paulo.

\section{METHODS}

\section{Population}

São Paulo city is the capital of the State of São Paulo, Brazil. It is crossed by the Tropic of Capricorn, located in the southeast Brazil, with around 10 million inhabitants, $97 \%$ living in the urban area [11]. The state education network of São Paulo comprises 2500 schools, including nurseries, kindergartens and first grade schools, corresponding to a school population of about 2 million children. This study was carried out in the State Education and WellFare System of São Paulo by a random sampling selection of 304 schools. In each school, seven children were chosen, aged 1-11 years old in 1992. The sampling technique is described elsewhere [12].

Caieiras is a small town located in the northern part of São Paulo city, also crossed by the Tropic of Capricorn, with about 30000 inhabitants in 1990, over $90 \%$ living in the urban area. Individuals were sampled by cluster, in families within randomly selected administrative regions, stratified by age (range: 1-15 years); children 3 years old or under were not enrolled in school. Out of the 62 administrative regions in the city, with 150 dwellings each, 32 were randomly selected [13].

\section{Serology}

Blood was taken by finger prick with Glucolet ${ }^{\mathrm{TM}}$ disposable lancet and collected into two $2.5 \mathrm{~cm}$ diameter circles of Whatman ${ }^{\circledR}$ No. 1 filter paper. Blood elution was done using $500 \mu 1$ of a phosphate buffered saline (PBS). Eluates were frozen and stored at $-20{ }^{\circ} \mathrm{C}$ for up to 5 years. The eluates were thawed for $12 \mathrm{~h}$ in refrigerator before being tested.

In São Paulo, 1112 eluates were tested for specific IgG antibody against VZV using an in-house ELISA technique as described elsewhere [14] and 656 eluates using a commercially available enzyme immunoassay (ELISA TEST-HRP, Hycor Biomedical GmbH, Kassel, Germany); 33 eluates were analysed by both methods. The agreement of the two different ELISA techniques was evaluated by Kappa analysis [15], and were considered concordant. In Caieiras, all 371 eluates were tested for specific IgG antibody against VZV using an in-house ELISA technique [14].

\section{Data management}

A database was created, recording identification and serological data of individuals. Results were analysed to determine the VZV antibody-positive proportion by age, and the respective $95 \%$ confidence interval (exact binomial method).

After establishing the proportion of VZV antibodypositive individuals for each age class $S_{1}^{+}(a)$, a continuous function was fitted, using a modification of a function proposed by Farrington [16].

$$
\begin{aligned}
S_{1}^{+}(a)=1- & \exp \left\{\frac { k _ { 1 } } { k _ { 2 } ^ { 2 } } \left[\left(k_{2}\left(a-L_{c}\right)+1\right)\right.\right. \\
& \left.\left.\times \exp \left(-k_{2}\left(a-L_{c}\right)\right)-1\right]\right\}, a \geqslant L_{c},
\end{aligned}
$$

where $k_{i}(i=1,2)$ are the fitting parameters to the seropositive function, and where $L_{c}=0.5$ year is the age until which there is the influence of maternally derived antibody protection.

Considering that children from São Paulo seem to come from two different exposure experiences, namely, children attending nursery facilities from the beginning of their lives and children entering graded school at 4 years of age or later, as revealed by the seroprevalence profile [15], it is necessary to split the fitting of the serological data in two parts in order to represent better the seroprofile. São Paulo force of infection will be estimated for nursery attendees.

Let $a^{*}$ be the age of transition from nursery to grade school. The VZV antibody-prevalence function under $a^{*}$ is given by equation (1). Let us assume that at age $a^{*}$ the proportion of VZV antibody-positive children, $s^{*}$, is lower due to the contribution of VZV 
antibody-negative children entering grade school at that age and presumably not as exposed as nursery children to VZV infection. Therefore, a correction must be applied to the seroprevalence fitting curve as follows:

$$
\begin{aligned}
S_{2}^{+}(a)=1- & \theta \exp \left\{\frac { k _ { 1 } } { k _ { 2 } ^ { 2 } } \left[\left(k_{2}\left(a-L_{c}\right)+1\right)\right.\right. \\
& \left.\left.\times \exp \left(-k_{2}\left(a-L_{c}\right)\right)-1\right]\right\}, \quad a \geqslant a^{*},
\end{aligned}
$$

where $\theta$ is the susceptibility ratio at age $a^{*}$ between primary school arrivers (mixing of children from household and nursery) and nursery leavers, given by

$\theta=\frac{1-S_{2}^{+}\left(a^{*}\right)}{1-S_{1}^{+}\left(a^{*}\right)}$

with $S_{1}^{+}(a)$ and $S_{2}^{+}(a)$ being given by equations (1) and (2), respectively.

Using the VZV antibody-prevalence continuous function as defined above, the per capita rate in which susceptibles were infected (force of infection), $\lambda(a)$, can be derived by the catalytic approach [17], applied to the formulation proposed by Farrington. The corresponding $\lambda(a)$ is

$\lambda(a)=k_{1}\left(a-L_{c}\right) \exp \left(-k_{2}\left(a-L_{c}\right)\right), \quad a \geqslant L_{c}$.

To simulate varicella transmission dynamics the model assumes a stationary age-dependent way of transmission. Based on the model developed by Massad et al. [18] we assumed that the total population was divided into susceptible, infected and recovered individuals.

In assuming an equilibrium situation, we could calculate the force of infection as follows [18]:

$$
\begin{aligned}
& \lambda(a)=\mu \int_{L_{c}}^{\infty} \mathrm{d} a^{\prime} \beta\left(a, a^{\prime}\right) \int_{L_{c}}^{a^{\prime}} \mathrm{d} a^{\prime \prime} \lambda\left(a^{\prime \prime}\right) \\
& \times \exp \left(-(\mu+\gamma) a^{\prime}\right) \exp \left(\gamma a^{\prime \prime}\right) \exp \left(-\int_{L_{c}}^{\alpha^{\prime \prime}} \lambda(s) \mathrm{d} s\right),
\end{aligned}
$$

where $\mu$ is a constant mortality rate, $\gamma$ is a recovery rate and $\beta\left(a, a^{\prime}\right)$ is an effective contact rate, defined as a continuous function which describes the contacts of susceptibles of age $a$ with infected of age $a^{\prime}$ and it also takes into account the probability of such contacts result in infection [18]. In the modelling, we have considered $\mu=0.017$ year $^{-1}$, equivalent to the inverse of the human life expectation, assumed as 60 years, and $\gamma=73.0$ year $^{-1}$, related to the inverse of a recovery period of 5 days [17].

Assuming that children are stratified mainly by age into classrooms the probability of contacts is maxi- mized between children of same age. Thus it is reasonable to model $\beta\left(a, a^{\prime}\right)$ as a symmetric function under changes between $a$ and $a^{\prime}$, i.e. $\beta\left(a, a^{\prime}\right)=\beta\left(a^{\prime}, a\right)$. To satisfy the above assumption, we have chosen:

$$
\begin{aligned}
\beta\left(a, a^{\prime}\right)= & b_{1}\left(a+a^{\prime}\right) \exp \left(-b_{2}\left(a+a^{\prime}\right)\right) \\
& \times \exp \left[\frac{-\left(a-a^{\prime}\right)^{2}}{\left(b_{3}+b_{4}\left(a+a^{\prime}\right)\right)^{2}}\right], \quad \text { for } a>L_{c},
\end{aligned}
$$

where $b_{i}(i=1,2,3,4)$ are the fitting parameters. This function is the product of a bell-shaped curve with an asymmetric function that resembles the force of infection $\lambda(a)$, given by equation (4). After the fitting of the seroprevalence function $S^{+}(a)$ and the estimation of $\lambda(a)$ by means of equation (4), we could estimate the parameters $b_{i}$ of the contact function by fitting the $\lambda(a)$ curve derived from equation (5) to $\lambda(a)$ related to the seroprevalence data, obtained from equation (4).

The average age of first infection $a_{\mathrm{av}}$, in persons eventually infected, is defined by the equation:

$a_{\mathrm{av}}=\frac{\int_{0}^{\infty} a \lambda(a) x(a) \mathrm{d} a}{\int_{0}^{\infty} \lambda(a) x(a) \mathrm{d} a}$,

where $x(a)$, the proportion of remaining susceptibles can be approximated by $\left[1-S^{+}(a)\right]$.

We can also define two other parameters related to the proportion of VZV antibody-positive individuals $S^{+}(a)$ : the age in which $\lambda(a)$ has its maximum value, $a_{\max }$, and the median age at which susceptibles acquire infection, $a_{\text {med }}$, corresponding to an age in which half of the population under study has become VZV antibody-positive, equivalent to $S^{+}\left(a_{\mathrm{med}}\right)=50 \%$.

The average force of infection is estimated by:

$\lambda_{\mathrm{av}}=\frac{\int_{0}^{\infty} \lambda(a) x(a) \mathrm{d} a}{\int_{0}^{\infty} x(a) \mathrm{d} a}$.

The integrals of the expressions (7) and (8) were evaluated in the interval from $L_{c}$ to the age $a_{1 \mathrm{im}}$, where $a_{\text {lim }}$ is the maximum age observed in the data samples. For São Paulo, we have considered $a_{\text {lim }}=12.0$ years and, for Caieiras, $a_{\mathrm{lim}}=16.0$ years.

\section{RESULTS}

The age VZV antibody-prevalence data is recorded in Table 1. The age interval over 10 years old is condensed. During 1992, the age VZV antibody- 
Table 1. São Paulo and Caieiras VZV antibody-prevalence by age (1992)

\begin{tabular}{|c|c|c|c|c|c|c|}
\hline \multirow[b]{2}{*}{ Age (years) } & \multicolumn{3}{|c|}{ São Paulo } & \multicolumn{3}{|c|}{ Caieiras } \\
\hline & No. & $\%$ pos & S.E. & No. & $\% \operatorname{pos}$ & S.E. \\
\hline 1 & 115 & 33 & 0.085 & 72 & 18 & $0 \cdot 088$ \\
\hline 2 & 175 & $63 \cdot 4$ & 0.071 & 49 & $24 \cdot 4$ & $0 \cdot 12$ \\
\hline 3 & 185 & $73 \cdot 5$ & 0.063 & 31 & $48 \cdot 3$ & $0 \cdot 175$ \\
\hline 4 & 154 & $65 \cdot 5$ & 0.075 & 30 & $53 \cdot 3$ & $0 \cdot 178$ \\
\hline 5 & 192 & $58 \cdot 8$ & 0.069 & 29 & $72 \cdot 4$ & $0 \cdot 162$ \\
\hline 6 & 185 & $71 \cdot 3$ & 0.065 & 24 & 87.5 & $0 \cdot 132$ \\
\hline 7 & 204 & $78 \cdot 9$ & 0.055 & 21 & $95 \cdot 2$ & 0.091 \\
\hline 8 & 196 & 79 & 0.056 & 16 & $93 \cdot 7$ & $0 \cdot 118$ \\
\hline 9 & 190 & $84 \cdot 7$ & 0.051 & 21 & $95 \cdot 2$ & $0 \cdot 091$ \\
\hline$\geqslant 10$ & 172 & $80 \cdot 2$ & 0.059 & 78 & $94 \cdot 8$ & $0 \cdot 048$ \\
\hline
\end{tabular}

S.E. $=$ standard error

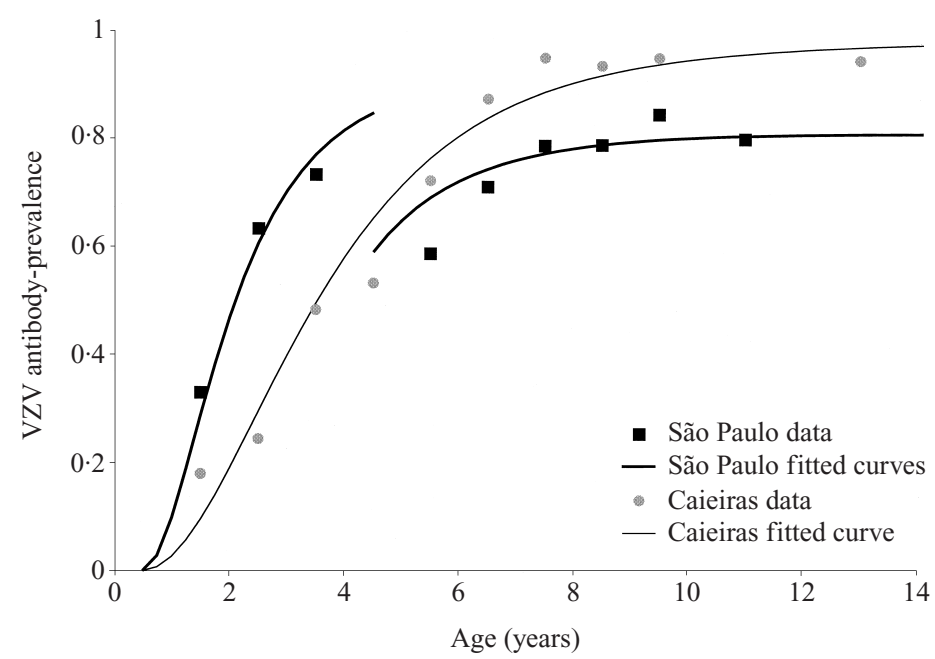

Fig. 1. São Paulo and Caieiras varicella VZV antibody-prevalence data and fitted curves.

prevalence data revealed that in Caieiras children, the VZV antibody-positivity rose slowly from $18 \%$ at 1 year of age to $90 \%$ at 6 years, then it remained stable around this value. We observed a higher proportion of VZV antibody-positive children $1-3$ years of age in São Paulo city, enrolled in nurseries or day-care centres, with a decrease in VZV antibody-positivity in children 4 and 5 years old. From 6 years of age, there was an increase in VZV antibody-positivity, reaching a plateau around $80-85 \%$ at 10 years of age.

To fit the São Paulo VZV antibody-prevalence data, we have taken into account the drop in the VZV antibody-positivity in children between 4 and 5 years old (Table 1), in accordance with the methodology described in the previous section, and considering $a^{*}$ $=4.5$ years. From the fit, we have obtained the susceptibility ratio at age $4 \cdot 5$ years, $\theta=2 \cdot 71 \pm 0 \cdot 44$. As we can see in Figure 1, the second part of the curve (from 4.5 years on) reaches a plateau at $80 \%$ of VZV
Table 2. VZV antibody-prevalence fitting parameters and standard error (S.E) for São Paulo and Caieiras

\begin{tabular}{lcl}
\hline \hline & São Paulo & Caieiras \\
\hline$k_{1}$ & 1.02 & 0.235 \\
$($ S.E) & 0.10 & 0.048 \\
$k_{2}$ & 0.617 & 0.222 \\
$($ S.E. $)$ & 0.04 & 0.055 \\
$\chi^{2}$ & 18.6 & 9.51 \\
\hline \hline
\end{tabular}

antibody-positivity. The Caieiras fitted curve shows a more gradual rise in VZV antibody-positivity until 5 years of age and a later stable pattern (Fig. 1). The fitting parameters, standard errors and goodness-offit $\chi^{2}$ test are shown in Table 2 .

Based on fitted seroprevalence $S^{+}(a)$, the resulting force of infection $\lambda(a)$ (equation (4)) for São Paulo and Caieiras are illustrated in Figure 2. We noted that 




Fig. 2. Varicella force of infection for São Paulo and Caieiras.

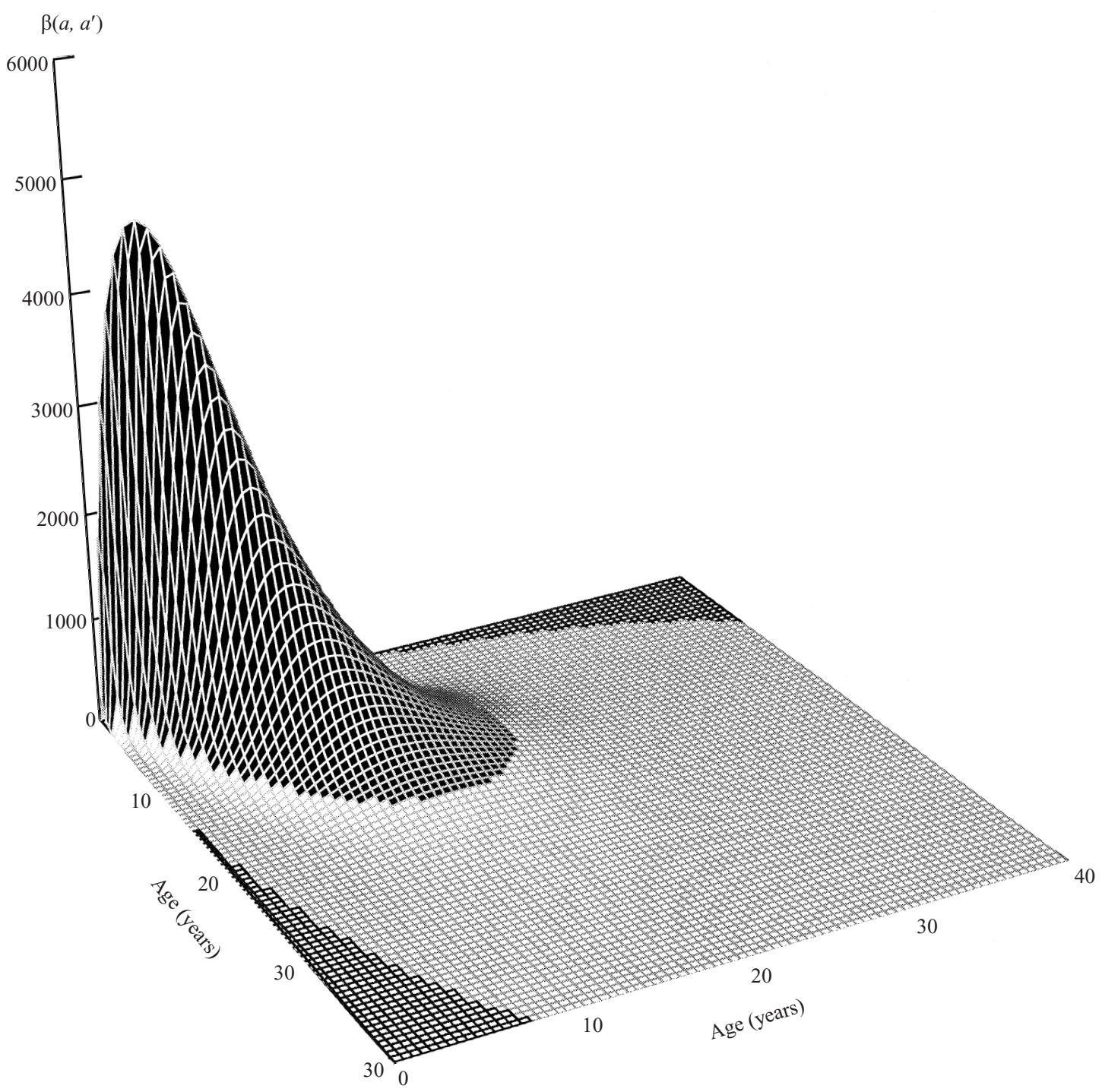

Fig. 3. São Paulo varicella contact rate $\beta\left(a, a^{\prime}\right)$. 


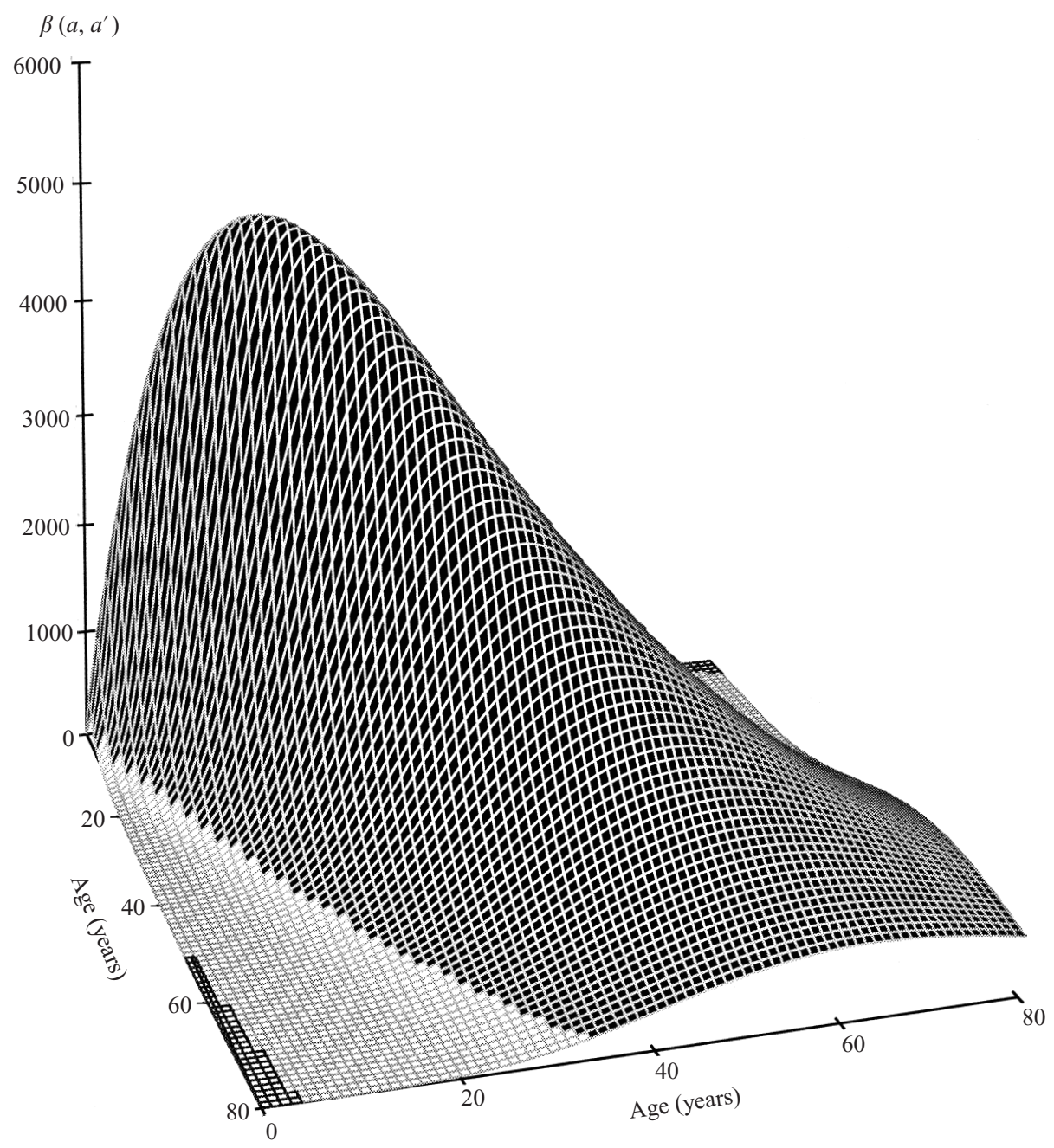

Fig. 4. Caieiras varicella contact rate $\beta\left(a, a^{\prime}\right)$.

the force of infection in São Paulo rose rapidly and it was concentrated in early childhood (around 2 and 3 years), dropping slowly and then coming close to null values after 12 years of age. The average force of infection estimated for São Paulo was 0.29 year ${ }^{-1}$.

In Caieiras, the curve presented a different profile with a slow ascendant and descendant phases, and it was present at around 5 years of age, and it did not come close to null values even at 16 years of age. The average force of infection estimated for Caieiras was $0 \cdot 26$ year $^{-1}$.

Those differences were also observed with the contact rate. In São Paulo (Fig. 3), the age dependent transmission coefficient $\beta\left(a, a^{\prime}\right)$, representing the contact between the susceptibles of age $a$ with the infected of age $a^{\prime}$ raised sharply in the first 3 years of age, reaching a maximum value at this age interval, dropping close to null values with age increment. In Caieiras (Fig. 4), a slow rise was noted, with more spreaded curve, reaching the maximum value later
Table 3. Varicella contact rate $\beta\left(a, a^{\prime}\right)$ fitting parameters for São Paulo and Caieiras

\begin{tabular}{lcc}
\hline \hline & São Paulo & Caieiras \\
\hline$b_{1}$ & $2143 \cdot 58$ & $411 \cdot 16$ \\
$b_{2}$ & $0 \cdot 1673$ & $0 \cdot 0300$ \\
$b_{3}$ & $0 \cdot 2654$ & $1 \cdot 968$ \\
$b_{4}$ & $0 \cdot 2915$ & $0 \cdot 2691$ \\
\hline \hline
\end{tabular}

and with the contact continuing along the age increase. The contact rate $\beta\left(a, a^{\prime}\right)$ fitting parameters are shown in Table 3.

The average age of first infection and its corresponding standard error was $2 \cdot 87 \pm 0 \cdot 14$ years and $4 \cdot 07 \pm 0.47$ years for São Paulo and Caieiras, respectively. The difference between these results was statistically significant $(P<0 \cdot 05)$. The calculated values for the median ages of infection, $a_{\text {med }}$, and for the ages corresponding to the $\lambda(a)$ maximum, $a_{\max }$, 
were $2 \cdot 10$ and $2 \cdot 12$ years for São Paulo.The $a_{\text {med }}$ and $a_{\max }$ values for Caieiras were 3.52 and 5.00 years.

\section{DISCUSSION}

Although less infectious than measles, varicella is nonetheless highly contagious, especially in closed populations, where secondary attack rates in susceptible household contacts is greater than $85 \%$. Social changes affecting contact among children influence its epidemiology, such as children gathering at school, where presumably children establish more contact $[3,5,6,9]$.

The results observed in this study outlined the differences related to social behaviour of children aged 1-3 years in São Paulo, attending all-day nurseries or kindergarten. These children interact socially, resulting in early exposure and providing means for efficient transmission of the viruses [20]. The early school entry determines groups of close acquaintance, increasing dissemination of infection with greater number of contacts among children of the same young age [3, 9]. São Paulo children 4 and 5 years old came from all-day nurseries or day-care centres, or they started school at this age. The observed decrease of VZV antibody-positivity at this age may have occurred due to the integration of children of different degrees of sociability. In addition, children at this age, spend less time (half-day) together in the school compared with younger children. A $90 \%$ VZV antibody-prevalence in children over 10 years old was also observed in São Paulo in 1993 and 1994, as published elsewhere [15]. This cross-sectional study from 1992 measured VZV antibody-prevalence in children 1-12 years of age in São Paulo. The observed steady fitted VZV antibody-prevalence around $80 \%$ after 6 years of age in São Paulo children resulted from data analysed until 12 years of age. The seroprevalence behaviour could not be estimated after this age.

Farrington's function was a simple model for $S^{+}(a)$ and can give us an approximate idea of the seroprevalence age-dependence. It enables us to estimate an approximate effective contact rate $\beta\left(a, a^{\prime}\right)$, as shown in Figures 3 and 4, which can be the basis for a future analysis of the prospective outcomes of a vaccination programme for varicella.

This study utilized a different form of age dependent transmission coefficient, presumably better reflecting the real situation. We assumed $\beta$ as an arbitrary agedependent continuous function which reflected the seroprevalence and it could substitute the contact matrix previously proposed [21].

The observed differences showed in the shape of $\lambda(a)$ and the age scale of $\beta\left(a, a^{\prime}\right)$ could be attributed to distinct epidemiological patterns between the studied populations. São Paulo children 1-3 years old spent more time with each other in the all-day nursery and kindergarten, consequently with higher contact among them.

Caieiras household children of this age interval presented a different degree of sociability, with the VZV antibody-positivity probably resulting from the infection introduction by school-aged children [3]. Considering that more susceptible children entered later in the school in Caieiras than in São Paulo, it is possible that they have had more social contacts later and therefore they had acquired infection at older ages.

The contact patterns among school and pre-school children play an essential role in the transmission dynamics of VZV, and it should be necessary to have a good comprehension of these patterns in order to assess the impact of a varicella control strategies.

\section{ACKNOWLEDGEMENTS}

The authors thank the anonymous referees for their very helpful suggestions and comments. This study was supported by FAPESP (Proc. 96/05675-9; and Proc. 97/03679-0), and PRONEX (41.96.0937.00).

\section{REFERENCES}

1. Arvin AM. In: Fields BN, Knipe, DM, Howley M, Chanock RM, Melnick JL, Monath TP, Roziman B, Straus SE, eds. Fields virology, 3rd ed. Philadelphia: Lippincott-Raven, 1996; 2547-51.

2. Takahashi M, Gershon AA. In: Plotkin, S A, Mortimer E A. eds. Vaccines 2nd edn. W B Philadelphia: Saunders, 1994; 387-97.

3. Wharton M. The epidemiology of varicella-zoster virus infections. Infect Dis Clin North Am 1996; 3: 571-81.

4. Preblud SR. Age-specific risks of varicella complications. Pediatrics 1981; 68: 14-7.

5. Hope-Simpson RE. Infectiousness of communicable diseases in the household (measles, chickenpox and mumps). Lancet 1952; ii: 549-54.

6. Ross AH, Lenchner F, Reitman G. Modification of chickenpox in family contacts by administration of gamma globulin. N Engl J Med 1962; 267: 369-76.

7. London WP, Yorke JA. Recurrent outbreaks of measles, chickenpox and mumps. I. Seasonal variation in contact rates. Am J Epidemiol 1973; 98: 453-68. 
8. Garnett GP, Cox MJ, Bundy DAP, Didier JM, Stcatharine $\mathrm{J}$. The age of infection with varicella-zoster virus in St-Lucia, West-Indies. Epidemiol Infect 1993; 110: $361-72$.

9. London WP, Yorke JA. Recurrent outbreaks of measles, chickenpox and mumps. II. Systematic differences in contact rates and stochastic effects. Am J Epidemiol 1973; 98: 469-82.

10. Massad E, Raimundo SM, Silveira ASB. A continuos function model for the age-related force of infection. Math Comput Modelling 1990; 13: 101-12.

11. SEADE - State Data Analysis System Foundation 1998; (URL: http://www.seade.gov.br).

12. Massad E, Azevedo-Neto RS, Burattini MN, et al. Assessing the efficacy of a mixed vaccination strategy against rubella in São Paulo, Brazil. Intl J Epidemiol, 1995; 24: 842-50.

13. Azevedo Neto RS, Silveira ASB, Nokes DJ, et al. Rubella seroepidemiology in a non-immunized population of São Paulo State, Brazil. Epidemiol Infect 1994; 113: 161-73.

14. Cristófani LM, Weinberg A, Peixoto V, et al. Administration of live attenuated varicella vaccine to children with cancer before starting chemotherapy. Vaccine 1991; 9: 873-6.

15. Yu ALF, Costa JM, Amaku M, et al. Three year seroepidemiological study of varicella-zoster virus in São Paulo, Brazil. Rev Inst Med Trop S Paulo 2000; 42: $125-8$.

16. Farrington CP. Modelling the forces of infection for measles, mumps, and rubella. Stat Med 1990; 9: 953-67.

17. Grenfell BT, Anderson RM. The estimation of agerelated rates of infection from case notifications and serological data. J Hyg 1985; 95: 419-46.

18. Massad E, Azevedo Neto RS, Yang HM, Burattini MN, Coutinho FAB. Modelling age-dependent transmission rates for childhood infections. J Biol Systems $1995 ; 3$ : 803-12.

19. Garnett GP, Grenfell BT. The epidemiology of varicella-zoster virus: a mathematical model. Epidemiol Infect $1992 ; \mathbf{1 0 8}$ : 495-511.

20. Kangro HO, Osman HK, Lan YL, et al. Seroprevalence of antibodies to human herpes viruses in England and Hong-Kong. J Med Virol 1994; 43: 91-6.

21. Anderson RM, May RM. In: Infections diseases of humans: dynamics and control. Oxford: Oxford University Press, 1992: 172-206. 